\title{
Effect of MDGs/NTI Primary School Teachers' Retraining Workshop on Pupils' Achievement in Mathematics in Kwara State, Nigeria
}

\author{
Adeniyi, C. O. ${ }^{1}$; Hassan, M. O. ${ }^{2} \&$ Ogundele, L. O. ${ }^{3}$ \\ ${ }^{1 \&}{ }^{3}$ Mathematics Department, Kwara State College of Education, Oro, Nigeria \\ ${ }^{2}$ Mathematics Department, Kwara State College of Education (T), Lafiagi, Nigeria
}

\begin{abstract}
This study sought out the effect of MDGs/NTI primary school teachers' re-training workshop on pupils' achievement in mathematics in Kwara State, Nigeria. A total of 192 pupils were involved as sample. A Teacher Made Achievement Test (TMAT) in mathematics was used as instrument for the study. T-test statistic was used to test the two formulated hypotheses. It was discovered that there was significant difference between the achievement of pupils taught by teachers who attended the MDGs/NTI retraining workshop and pupils taught by teachers who did not attend the workshop. It is recommended among others that regular workshops, seminars and conferences should be organized for teachers in the state in order to enhance productivity in the education sector.
\end{abstract}

Keywords: achievement, millennium development goals, retraining, workshop.

\section{Introduction}

The quest for eradication of illiteracy in the modern society is a basic concern of every society of the world. This is because education is one of the vital indices used in the categorization of nations as developed or developing nation. For Nigeria to be categorized as a developed nation, she must get rid of illiteracy among its citizens by ensuring that every member of the society has access to quality education.

Education is an instrument a society can use to solve her problems. Obiageli $(2006)^{[1]}$ noted that education alone, if well planned and delivered, is capable of strengthening the nation's democracy and engendering economic growth. Thus, education is an essential phenomenon through which human and natural resources are harnessed for the common good of humanity. UNESCO $(2003)^{[2]}$ asserted that all nations should ensure that education is a right for all her citizens.

Basic education is referred to as the foundation upon which the rest of the educational system is built. One of the objectives of basic school education in Nigeria is to inculcate in children, permanent literacy and numeracy and the ability to communicate effectively (FRN, 2004) ${ }^{[3]}$

The proper implementation of any curriculum depends on the quality of the teachers. The need to update the knowledge of the basic school teachers who are responsible for the implementation of the basic education curriculum at that level is paramount. The Federal Government of Nigeria recognized this fact as basic school teachers were involved in the nationwide millennium development Goals (MDGs) re-training workshop since 2006 for the development of teaching skills in the four core subjects in Basic school, namely: English Language, Mathematics, Basic Science and Technology and Social studies including the development of instructional materials. The workshop was organized by the National Teachers' institute (NTI), Kaduna, Nigeria on behalf of the federal ministry of education of Nigeria for basic school teachers in all the six geopolitical zones in the country.

According to Ahmed (2006) ${ }^{[4]}$, Millennium Development Goals (MDGs) projects of the NTI which started in 2006 involved re-training of 145,000 primary school teachers across the federation between $4^{\text {th }}$ and $29^{\text {th }}$ September 2006. Training covered innovative ways of teaching primary school core subjects (English Language, Mathematics, Science and Social Studies), improvisation of instructional materials, school-based assessment, basic computer skills and sensitization of teachers on the new 9-year basic education curricula. In addition, NTI used experienced consultants and resource persons in the training that was conducted in 4 centers in each state of the federation.

Sharehu $(2009)^{[5]}$ observed that in Nigeria, unlike other countries, the re-training of teachers had not received the desired attention from Local, State and federal Government. This is because there has not been any systematic attention to update regularly the knowledge and skills of teachers in the light of the changes in the basic school curriculum. It is this neglect that in turn affect the quality of teaching in the basic schools. It is in the recognition of this that the federal government of Nigeria under the Millennium Development Goals projects directed the National teachers' institute, Kaduna to re-train basic school teachers. 
The success or failure of any programme depends on the teachers. The Nigeria policy on education has made it clear that no educational system can rise above the quality of its teachers (FRN, 2004) ${ }^{[3]}$. This means that teacher is the pivot on which the success of any educational programme hangs. It also goes further to explain that the quality of education in the country is parallel with the efficiency and effectiveness of the teachers. According to Onwuka (1996) ${ }^{[6]}$, a designed curriculum depends on the teachers' effectiveness and efficiency in order to achieve the set goals and objectives of the curriculum planners.

Mathematics is the key and backbone of almost all the school subjects (Ayinla, 2011) ${ }^{[7]}$. It is a compulsory subject at both primary and secondary school level of education. As important as mathematics is, it is disheartening to see that students perform poorly in the subject. This poor performance by students especially at the basic school level prompted the attention of both the state and federal government to initiate a nationwide re-training of primary school teachers to enhance their efficiency in the teaching and learning of mathematics by the NTI through the MDGs programme.

\section{Statement Of The Problem}

Students have great difficulty in learning, understanding and comprehending mathematics taught by their teachers. The high rate of failure of the subject despite the huge amount of money committed to education by government at all levels is a concerns to all and sundry. Hence, as a way of helping solving the long standing students' poor performance in mathematics in Nigeria, this study was carried out in Kwara state, Nigeria to determine whether or not the annual retraining workshop organized by NTI under the Millennium Development Goals had any effect on pupils' performance in Mathematics.

\section{Purpose Of The Study}

The main purpose of this study was to finding out whether the NTI/MDGs retraining workshop organized by the NTI for teachers in Kwara State has the required effect on the pupils' performance in Mathematics.

\section{Significance Of The Study}

It is assumed that the study would be of tremendous benefit to Nigerian basic schools teachers on the need to attend the MDGs/NTI retraining workshop.

Finally, the findings of this study would encourage the government to organize more seminars, workshop, conferences etc for teachers in order to encourage teachers' effectiveness and efficiency for students' better academic performance.

\section{Research Questions}

The following research questions were raised and answered for the purpose of this study

i. would there be difference in the academic performance of students taught Mathematics teachers who attended the MDGs/NTI retraining workshop and those taught by Mathematics teachers who did not attend the training?

ii. would gender influence the academic performance students taught Mathematics by the teachers who attended the MDGs/NTI retraining workshop?

\section{Research Hypothesis}

The following null hypotheses were formulated to guide the study:

HO$_{1}$ : There is no significance difference between the performance of pupils taught by teachers who attended the MDGs/NTI retraining workshop and those taught by the teachers who did not attend the training

$\mathbf{H O}_{2}$ : There is no significance difference between the performance of male students and female students taught by teachers who attended the MDGs/NTI retraining workshop.

\subsection{Research Design}

\section{Methodology}

The study is a quasi-experimental of pre-test, post-test, non-randomize, non equivalent, Control group design involving a $2 \times 2$ factorial type. The Instructional Strategy is at two levels (Teacher who attended the MDGs/NTI retraining workshop and teacher who do not attend the workshop), while the gender is at two levels (Male and Female). 


\subsection{Sampling Techniques}

The target population for this study was all the basic V students in Kwara State, Nigeria. Three schools were selected for the study (One in each senatorial district of the state). One arm of each of the selected schools was used as experimental class while the other arm of each of the selected schools was used as control class. Intact classes were used. A total number of 194 basic V students were involved (The experimental group has 99 students and control group has 95 students).

\subsection{Research Instrument}

The instrument used for the study was a Teacher Made Achievement Test (TMAT) prepared by the researchers for the purpose of this research work. The TMAT comprised 20 multiple choice questions drawn from topics in Basic V mathematics curriculum. The instrument was validated by two Mathematics Lecturers and one expert in measurement and evaluation from Kwara State College of Education, Oro, Nigeria for proper scrutiny and necessary corrections.

\subsection{Procedure for Data Collection}

The Teachers Made Achievement Test (TMAT) was administered as pre-test on students in the three selected Basic Schools. After administering the pre-test, the teachers were trained through MDGs/NTI retraining workshop and necessary materials were provided. After the training, the teachers taught their students for four weeks during which only the experimental groups were taught by teachers who attended MDGs workshop organized by NTI while the control groups were taught by teachers who did not attend the workshop. At the end of the instruction, the pre-test instrument, that is TMAT, were re-organized and administered as posttest to both the experimental and the control groups, thus marking the end of the experiment.

\subsection{Data Analysis Techniques}

The TMAT scores formed the basis of data analysis. The research hypotheses one and two were tested with t-test statistical analysis.

\section{Results}

The analyses of the scores collected from the treatment of the study, pre-test and post test of the experimental groups (students taught by the teachers who attended MDGs/NTI retraining workshop) and the control groups (students taught by the teachers who did not attend the MDGs/NTI retraining workshop). The scores were analyzed using t-test analysis and Analysis of Variance based on the three formulated null hypotheses with an alpha level of 0.05 .

\subsection{Research Hypothesis One:}

There is no significance difference between the performance of pupils taught by teachers who attended the MDGs/NTI retraining workshop and those taught by the teachers who did not attend the training

Table 1: t-test analysis of posttest scores of experimental and control groups

\begin{tabular}{|c|c|c|c|c|c|c|c|}
\hline Group & No & Mean & Std D & Df & $\mathbf{t}_{\mathrm{cal}}$ & $\mathbf{t}_{\mathrm{tab}}$ & Remark \\
\hline $\begin{array}{l}\text { Experimental } \\
\text { Group }\end{array}$ & 99 & 11.9 & 3.19 & & & & \\
\hline Control Group & 95 & 6.6 & 3.42 & 192 & 77.49 & 1.96 & Significant \\
\hline
\end{tabular}

Table 1 above reveals that the t-calculated value of 77.49 is significantly greater than the table-value of 1.96. This shows that the hypothesis which states that there is no significant difference between the post test scores of students taught by teachers who attended the MDGs/NTI re-training workshop and students taught by teachers who did not attend the training is hereby rejected. Thus, there is a significance difference between the performance of pupils taught by teachers who attended the MDGs/NTI retraining workshop and those taught by the teachers who did not attend the training. This is in line with the result of Momoh (2009) ${ }^{[8]}$ that stated that students taught by teachers who attended retraining workshop performed better than those students taught by the teachers who did not attend such retraining workshop.

\subsection{Research Hypothesis Two:}

There is no significance difference between the performance of male students and female students taught by teachers who attended the MDGs/NTI retraining workshop. 
Table 2: t-test analysis of posttest scores of Male and Female students in experimental groups

\begin{tabular}{llllllll}
\hline Group & No & Mean & Std D & Df & $\mathbf{t}_{\text {cal }}$ & $\mathbf{t}_{\text {tab }}$ & Remark \\
\hline Female & 61 & 12.16 & 3.00 & & & & Significant \\
Male & 38 & 11.6 & 2.99 & 97 & 0.902 & & \\
\hline
\end{tabular}

*significant at 0.05 level

Table 2 above reveals that the $t$-test calculated of 0.902 is less than the $t$-table value of 1.96 . Thus, the hypothesis which states that there is no significant difference between the posttest scores of female and male students taught by teachers who attended the MDGs/NTI retraining workshop is not rejected. The result indicates that gender issue has no significant difference on students' academic achievement.

\section{Conclusion}

In the basic school curriculum, mathematics is one of the core subjects in Nigeria schools. The performance of students in mathematics has not been encouraging in the state in particular and Nigeria in general. This ugly situation needs to be addressed and the annual retraining workshop organized by NTI in Nigeria since 2006 would go a long way in improving the teachers qualities and efficiency which would in turn improve students academic performance mathematics and other subjects as well.

\section{Recommendations}

Based on the findings of this study, the following recommendations were made

1. Government should continue to invest in education especially mathematics education which is the bed rock of development in science, information and technology

2. Government should ensure the retraining workshop go round all the teachers in nation not for selected few for teaching efficiency

3. The trained teachers should serve as mentors to others

4. Regular workshops, seminars and conferences should be organized for teachers in the state

5. There should be a follow up for all kinds of seminars, retraining and workshops organized for teachers in order to determine its impact on students' academic performance.

\section{References}

[1] E. Obiageli, Education reform agenda. (Abuja: FMOE Press, 2006)

[2] UNESCO, Early childhood Education. Retrieved 3/6/2008 at unesco.org/edu/en/phpURL, 2003

[3] Federal Republic of Nigeria, National policy on education (Yaba: NERDC Press, 2004)

[4] M. Ahmed, National Teachers' Institute: Social studies, (Kaduna: NTI Press,2006)

[5] A. L. Sharehu, National Teachers' Institute: Social studies, (Kaduna: NTI Press, 2009)

[6] U. Onwuka, Curriculum development for African (Publishers Ltd. Second Edition, 2009)

[7] J. O. Ayinla, Effect of teachers' instructional strategy pattern on senior school students' performance in mathematics word problems in Ondo, Nigeria. M.Ed. Dissertation, University of Ilorin, Ilorin, Nigeria, 2011.

[8] S. O. Momoh, Effect of the retraining workshop for mathematics teachers in junior secondary classes on students' achievement in mathematics in Kogi State. ABACUS: Journal of Mathematical Association of Nigeria (MAN), 34 (1), 2009, 140 - 145. 